\title{
Surgical Management of Avulsion Fracture of the Point of Hock in a Malabari Goat by Tension Band Wiring-A Case Report
}

\author{
B. M. Nijin Jos* \\ Kerala Animal Husbandry Department, Veterinary Surgeon, District Veterinary Centre, \\ Kollam, India \\ *Corresponding author
}

\begin{abstract}
A B S T R A C T
\section{Keywords}

Malabari goat, Avulsion fracture, Tension band wiring,

Radiographic examination

\section{Article Info}

Accepted:

22 June 2020

Available Online:

10 July 2020

\section{Introduction}

Avulsion fracture occurs when the fractured fragment of the bone gets pulled away by the tendon attached it. If left untreated this condition can lead to deformity, nonunion, malunion, pain and disability (Vannabouathong et al., 2018). Such types of fractures are more commonly seen in younger individuals who are generally more active (Stevens et al., 1999). The normally adopted external coaptation techniques also fails to provide desired results. A six month old malabari goat presented with lameness was
\end{abstract}

diagnosed with the avulsion fracture of point of hock was surgical corrected by tension band wiring to provide an uneventful recovery.

\section{Anamnesis and Diagnosis}

A six month old malabari goat was presented with the complaint that the goat is unable to bear weight with its left hind limb following jumping from a height.

On examination loss of mobility was noticed and pain was evinced while palpating the 
hock joint. On radiographic examination the condition was diagnosed as Avulsion fracture of the left point of hock.

\section{Surgical procedure}

The animal was anaesthetized with xylazine hydrochloride at the dose rate of $0.1 \mathrm{mg}$ per kilogram intramuscularly and diazepam at the rate of $0.2 \mathrm{mg}$ per kilogram intravenously. The surgical site was clipped, shaved and prepared for aseptic surgery. A skin incision was made in the caudal aspect of the hock joint. The incision was deepened by blunt dissection. The fracture fragment was exteriorized. A Stienmann pin was passed from the dorsal aspect of the fractured fragment and into the distal fragment, tuber calcis. The pin was cut after retaining a small portion outside the fractured fragment and it was bend to make into a hook. A horizontal tunnel was made distal to the fracture line in the tuber calcis. A $22 \mathrm{G}$ stainless steel wire was passed through the tunnel and it was made into a figure of eight in the caudal aspect of tuber calcis and the ends of the wire was fixed over the bend portion of the stienmann pin. The wound was closed in routine manner. The affected limb was immobilized with a gutter splint. Post operatively the animal was maintained on antibiotics and other supportive therapy for five days.

\section{Results and Discussion}

A six months old malabari goat presented with lameness following jumping from a height was diagnosed as Avulsion fracture of the point of hock of left hind limb was surgically corrected by tension band wiring. The animal was reported to have recovered uneventfully.

Fig.1 Pre-operative radiograph

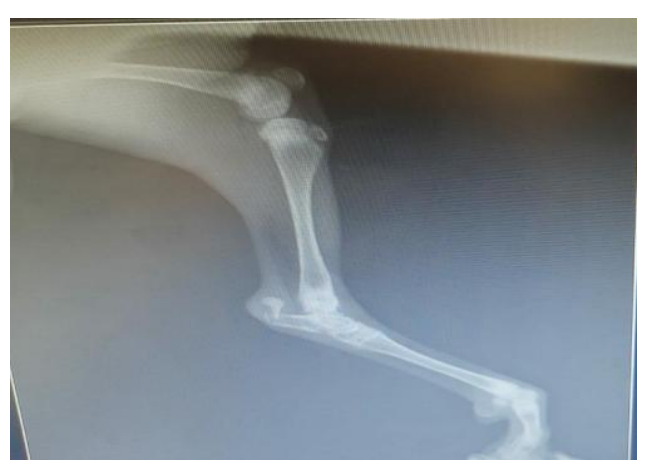

Fig.2 Post-operative radiograph

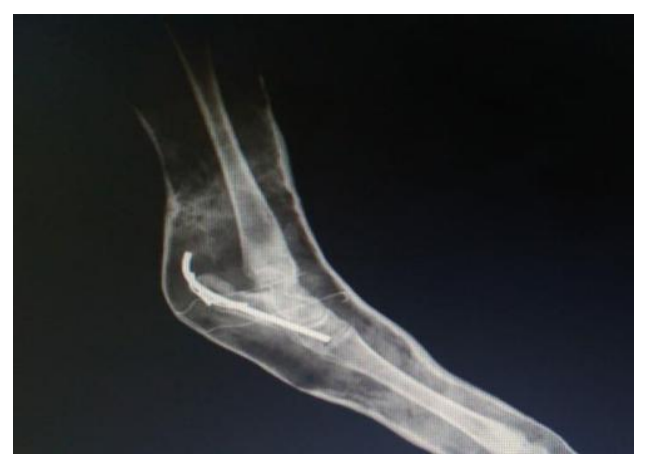


Fracture of the point of hock can be categorised as an avulsion fracture and its pattern of treatment is same as that is adopted in the case of avulsion fracture of olecranon process. Such fixation techniques have been described by Kachwaha et al., 2012 and Srinivasa Murthy et al., 2010 in case of fracture of olecranon process. As per Palmer et al., 1988 tension band wiring can also be combined with lag screw technique as fixation technique in case of olecranon osteotomies. The present case of tension band wiring done in a six months old malabari goat, showed good healing and weight bearing by four weeks post operative.

\section{Acknowledgment}

The author would like to thank Director, Kerala Animal Husbandry Department, District Animal Husbandry Officer, Kollam and Chief Veterinary Officer, District Veterinary Centre Kollam for providing the facilities for the successful completion of the work.

\section{References}

Kachwaha, K., Quazi, J. A. and Gahlot, T. K.2012. Tension Band Wiring and Pinning for the Management of Olecranon Fracture in a Dog. Intas Polivet. 13 (II): 391-392.

Palmer, R. H., Aron, D.N. and Chambers J.N. 1988. Acombined tension band and lag screw technique for fixation of olecranon osteotomies. Vet. Surg. 17: 328-332.

Srinivasa Murthy, K. M., Arif Basha M. K., Mahesh, V., Manjunatha, D. R. and Ranganath, L.2010. Tension band wiring for avulsion fracture of Olecranon in a Dog. Vet. World. 3(11):513-514.

Stevens. M. A., El-Khoury, G. Y., Kathol, M. H., E A Brandser, E. A. and Chow, S.1999. Imaging Features of Avulsion Injuries. Radiographics. 19(3) 655-672.

Vannabouathong, C. Ayeni, C.O. R. and Bhandari, M.2018. A Narrative Review on Avulsion Fractures of the Upper and Lower Limbs Clin. Med. Insights Arthritis Musculoskelet. Disord. 11.

\section{How to cite this article:}

Nijin Jos, B. M. 2020. Surgical Management of Avulsion Fracture of the Point of Hock in a Malabari Goat by Tension Band Wiring-A Case Report. Int.J.Curr.Microbiol.App.Sci. 9(07): 3639-3641. doi: https://doi.org/10.20546/ijcmas.2020.907.424 